\title{
Astragalus polysaccharide protects formaldehyde- -induced toxicity by promoting NER pathway in bone marrow mesenchymal stem cells
}

\author{
Yali She ${ }^{1,2 *}$, Xiaowen Zhao ${ }^{1 *}$, Pingfan Wu${ }^{1}$, Ling Xue ${ }^{1}$, Zhe Liu ${ }^{1}$, Meng Zhu ${ }^{1}$, Jie Yang1, \\ Yaling $\mathrm{Li}^{1,2}$
}

${ }^{1}$ Department of Pathology, School of Basic Medicine, Gansu University of Chinese Medicine, Lanzhou, Gansu, China

${ }^{2}$ Provincial-Level Key Laboratory of Molecular Medicine of Major Diseases and Study on Prevention and Treatment of Traditional Chinese Medicine, Gansu University

of Chinese Medicine, Lanzhou, Gansu, China

*These authors contributed equally to this work.

\begin{abstract}
Introduction. In our previous study, it has been confirmed that formaldehyde (FA) not only inhibits the proliferative activity, but also causes DNA-protein crosslinks (DPCs) formation in bone marrow mesenchymal stem cells (BMSCs). The purpose of this study was to detect the protective effect of astragalus polysaccharide (APS) against the cytotoxicity and genotoxicity of BMSCs exposed to FA, and to explore potential molecular mechanisms of APS activity.

Material and methods. Human BMSCs were cultured in vitro and randomly divided into control cells (Ctrl group), FA-treated cells (FA group, $120 \mu \mathrm{mol} / \mathrm{L}$ ), and cells incubated with FA and increasing concentrations $(40,100$, or $400 \mu \mathrm{g} / \mathrm{mL})$ of APS (FA + APS groups). Cytotoxicity was measured by MTT assay. DNA strand breakage, DNA-protein crosslinks (DPCs), and micronucleus formation were respectively detected by comet assay, KCl-SDS precipitation assay, and micronucleus assay. The mRNA and protein expression level of xeroderma pigmentosum group A (XPA), xeroderma pigmentosum group C (XPC), excision repair cross-complementation group 1 (ERCC1), replication protein A1 (RPA1), and replication protein A2 (RPA2) were all detected by qRT-PCR and Western Blot.

Results. Compared with the FA group, the cytotoxicity, DNA strand breakage, DPCs, and micronucleus levels were decreased significantly in FA + APS groups $(P<0.01)$. Meanwhile, the mRNA and protein expression of XPA, XPC, ERCC1, RPA1, and RPA2 were up-regulated significantly in the FA + APS groups $(P<0.05)$ with the most prominent effect of the $100 \mu \mathrm{g} / \mathrm{mL}$ APS.

Conclusions. Our results suggest that APS can protect the cytotoxicity and genotoxicity of human BMSCs induced by FA. The mechanism may be associated with up-regulated expression of XPA, XPC, ERCC1, RPA1, and RPA2 in the nucleotide excision repair (NER) pathway which promotes DNA damage repair. (Folia Histochemica et Cytobiologica 2021, Vol. 59, No. 2, 124-133)
\end{abstract}

Key words: astragalus polysaccharide; formaldehyde; bone marrow mesenchymal stem cells; toxicity; NER pathway; DNA strand breakage; DNA-protein crosslinks; micronucleus formation

\footnotetext{
Correspondence address: Yaling Li, MD

Provincial-Level Key Laboratory of Molecular

Medicine of Major Diseases and Study on Prevention

and Treatment of Traditional Chinese Medicine,

Gansu University of Chinese Medicine, Lanzhou, Gansu, China

phone 808-692-1554, fax: 808-692-1973

e-mail: liyaling_09@sina.com
}

This article is available in open access under Creative Common Attribution-Non-Commercial-No Derivatives 4.0 International (CC BY-NC-ND 4.0) license, allowing to download articles and share them with others as long as they credit the authors and the publisher, but without permission to change them in any way or use them commercially. (C)Polish Society for Histochemistry and Cytochemistry 


\section{Introduction}

As one component of bone marrow (BM), bone marrow mesenchymal stem cells (BMSCs) not only have multi-differentiation potential, but also can regulate the normal proliferation and differentiation of hematopoietic stem cells $[1,2]$. Thus, if BMSCs undergo toxic damage, BMSCs will lose their normal control over hematopoietic stem cells which may lead to myeloid leukemia.

Formaldehyde (FA), an environmental pollutant, is widely present in pollution, tobacco smoke and home accessories [3, 4]. The International Agency for Research on Cancer (IARC) indicated that FA may cause leukemia but the mechanisms remain unclear [4]. FA exhibits toxic effects in various types of mammalian cells, including cultured human myeloid progenitor cells and bone marrow blood progenitor cells in vivo [5, 6]. In our previous study, it has been confirmed that FA induced the excessive DNA-protein crosslinks (DPCs) in murine BMSCs [7].

The formation of DPCs is related to oxidative damage caused by FA-induced excessive hydroxyl free radicals [8-10]. DPCs are the primary DNA damage products induced by FA, and the level of DPCs is considered to be a good molecular dosimeter to assess FA-related cancer risk [11]. When FA induces DNA damage, such as DPCs, the cell activates repair mechanisms to reverse the damage to reestablish stability of the genome. The nucleotide excision repair (NER) pathway is an important way for DNA damage repair, which mainly repairs the cyclobutane pyrimidine dimer, DNA adducts, and cross-linking between chains $[12,13]$. It was found that the repair of FA-induced DPCs mainly depends on the NER pathway [14].

Astragalus membranaceus, belonging to the Leguminosae family, is used as a Qi-tonifying herb in traditional Chinese medicine [15]. Astragalus polysaccharide (APS), one of the active ingredients of Astragalus, has been shown to possess antioxidant, immunomodulatory, and tumor growth inhibitory properties in modern studies [16-18]. Numerous animal and anecdotal human data show that APS has anticancer effects in preclinical studies [19], as well as can improve myelosuppression induced by cytotoxic agents and chemopreventive effects [20]. APS enhanced the secretion of granulocyte colony-stimulating factor (G-CSF) and maintained the stability of the bone marrow hematopoietic microenvironment after chemotherapy [21]. In addition, APS could inhibit ionizing radiation-induced bystander effects in BMSCs [22] as well as inhibit apoptosis and senescence of BMSCs caused by ferric ammonium citrate iron overload [23].
The present study was performed to characterize the protective effect of APS against the cytotoxicity and genotoxicity of BMSCs exposed to FA. Subsequently, we used the qRT-PCR and Western Blot to assess the expression of xeroderma pigmentosum group A (XPA), xeroderma pigmentosum group C (XPC), excision repair cross-complementation group 1 (ERCC1), replication protein A1 (RPA1), and replication protein A2 (RPA2) genes in the NER pathway in FA- and APS-exposed BMSCs to explore potential molecular mechanisms of APS's activity.

\section{Materials and methods}

Cell culture. Human BMSCs (Cyagen Biosciences Inc, Santa Clara, CA, US) were cultured in Dulbecco's Modified Eagel Media: Nutrient Mixture F-12 1:1 Mixture (D-MEM/ /F12) supplemented with $10 \%$ fetal bovine serum for stem cells, $315 \mathrm{mg} / \mathrm{L}$ D-glucose and glutamine (all from Cyagen Biosciences, Santa Clara, CA, USA) at $37^{\circ} \mathrm{C}$ in a humidified incubator with $5 \% \mathrm{CO}_{2}$ (SANYO Electric CO., Ltd, Osaka, Japan). During the logarithmic growth period, the cells were detached with $0.25 \%$ trypsin- $0.02 \%$ EDTA.

Preparation of astragalus polysaccharide (APS) and formaldehyde (FA). The mass fraction of APS (Solarbio Science \& Technology Co., Ltd., Beijing, China) was more than $98 \%$. APS was dissolved and diluted to the final concentration of 40, 100, $400 \mu \mathrm{g} / \mathrm{mL}$ with D-MEM/F12. FA's (SigmaAldrich, St. Louis, MO, USA) mass fraction was more than $37 \%$. FA was diluted with D-MEM/F12 to the final concentration of $120 \mu \mathrm{mol} / \mathrm{L}$.

Groups. BMSCs were randomly divided into control group, FA group, and FA + APS 40, 100 and $400 \mu \mathrm{g} / \mathrm{mL}$ groups. In the control group, the cells were cultured with D-MEM/F-12. The cells in the FA group were cultured with $120 \mu \mathrm{mol} / \mathrm{L}$ FA of D-MEM/F-12. BMSCs co-cultured with $120 \mu \mathrm{mol} / \mathrm{L}$ FA and 40, 100, $400 \mu \mathrm{g} / \mathrm{mL}$ APS of D-MEM/F-12 served as FA + APS 40, 100 and $400 \mu \mathrm{g} / \mathrm{mL}$ groups. FA and APS were added at the same time and incubated together with BMSCs for $24 \mathrm{~h}$.

MTT assay. Cell proliferation activity was measured by MTT assay. The number of cells was adjusted to $4 \times 10^{3}$ per well and inoculated on 96-well plates. Then MTT (Biowest, Loire Valley, France) $20 \mu \mathrm{L}$ was added into cells and incubated for $4 \mathrm{~h}$. The supernatant was discarded and then DMSO was added before oscillation. The absorbance (A) value was measured at $490 \mathrm{~nm}$ with the enzyme marker (Bio-Rad, Hercules, CA, USA). The cell proliferation rate of each experimental group was calculated according to the formula: cell proliferation rate $=(\mathrm{A}$ experiment $-\mathrm{A}$ blank $) /($ A control - A blank $) \times 100 \%$. 
Table 1. The sequence of each primer in qRT-PCR

\begin{tabular}{|c|c|c|c|}
\hline mRNA & & Primer sequence & Product length \\
\hline \multirow[t]{2}{*}{ XPA } & Forward primer & 5'-CTACTGGAGGCATGGCTAAT-3' & $132 \mathrm{bp}$ \\
\hline & Reverse primer & 5'-CCATAACAGGTCCTGGTTGA-3' & \\
\hline \multirow[t]{2}{*}{$\mathrm{XPC}$} & Forward primer & 5'-ACTGCGCAGCCAGAAATCC-3' & $107 \mathrm{bp}$ \\
\hline & Reverse primer & 5'-CTTTGGAGAGAAGGCTCTTC-3' & \\
\hline \multirow[t]{2}{*}{ ERCC1 } & Forward primer & 5'ATGGACCCTGGGAAGGACA-3' & $133 \mathrm{bp}$ \\
\hline & Reverse primer & 5'-TCTGTGTAGATCGGAATAAGG-3' & \\
\hline $\begin{array}{l}\text { RPA1 } \\
\text { RAP2 }\end{array}$ & $\begin{array}{l}\text { Forward primer } \\
\text { Reverse primer } \\
\text { Forward primer } \\
\text { Reverse primer }\end{array}$ & $\begin{array}{l}\text { 5'-ATGCAGAAGGGGGATACAA-3' } \\
\text { 5'-ACTGTGTCGCCAACATGAA-3' } \\
\text { 5'-ATGACAGCTGCACCCATG-3' } \\
\text { 5'-TGTTCTGAAAAGATCTCAGG-3' }\end{array}$ & $\begin{array}{l}145 \mathrm{bp} \\
124 \mathrm{bp}\end{array}$ \\
\hline
\end{tabular}

Comet assay. Comet assay was used to detect DNA strand breakage. The normal 1\% melting point agarose gel (Biowest) was prepared on frosted-glass slides. The cell suspension was spread onto normal $1 \%$ melting point agarose gel after it was mixed with $1 \%$ low melting point agarose (volume ratio: 1:3) and then immersed in a lysis buffer containing $40 \%$ proteinase K (Promega, Madison, WI, USA) for lysis. Then it was immersed into the electrophoresis buffer for $30 \mathrm{~min}$ at $4^{\circ} \mathrm{C}$ in the darkness under the voltage of $15 \mathrm{~V}$, the current of $300 \mathrm{~mA}$. It was fixed with $1 \% \mathrm{H}_{2} \mathrm{O}_{2}$ and stained with propidium iodide (PI) for $30 \mathrm{~min}$. Cells were observed under IX81 fluorescence microscope (Olympus, Tokyo, Japan) and photographed. Twenty cells were randomly selected from each treatment group and the collected images were analyzed with comet experiment professional analysis software CASP (version 1.2.3; Bio-Rad). Olive tail moment (OTM), an internationally recognized value, was used to evaluate DNA strand breakage. The OTM value is equal to the distance between the center of mass and the density of the comet head and tail $\times$ the DNA content of the comet tail.

DNA-protein crosslinks formation assay. DPCs formation was detected by $\mathrm{KCl}-\mathrm{SDS}$ precipitation (KCl-SDS) precipitation assay. $2 \%$ SDS solution was added to cells that in the logarithmic growth stage, and the cells were lysed in the water bath at $65^{\circ} \mathrm{C}$. Then $1 \mathrm{~mol} / \mathrm{L}$ of $\mathrm{KCl}$ was added to the cells for fully mixing and an ice bath was used for $5 \mathrm{~min}$ to form SDS- $\mathrm{K}^{+}$precipitation. The pellet and supernatant containing free DNA were collected after centrifugation. The collected precipitate was added with $40 \%$ protease $\mathrm{K}$ and digested in a water bath at $50^{\circ} \mathrm{C}$. The supernatant containing DNA in DPCs was collected after centrifugation. $1 \mathrm{~mL}$ of the supernatant containing free DNA and crosslinked DNA was taken and Hoechst33258 (Biyuntian Biotechnology Co., Ltd., Shanghai, China) was added to it for staining for $30 \mathrm{~min}$. The standard curve was based on calf thymus DNA. Fluorescence values of each group were measured by RF-5301PC fluorescence spectrometer (Shimadzu, Tokyo,
Japan) under excitation light at $353 \mathrm{~nm}$ and emission light at $455 \mathrm{~nm}$. The concentrations of free DNA and cross-linked DNA were quantified according to the standard curve. The DPCs level was calculated by the following formula: DPCs $=$ cross-linked DNA concentration/(cross-linked DNA concentration + free DNA concentration) $\times 100 \%$.

Micronucleus assay. Cells were digested by trypsin and collected. Then hypotonic $\mathrm{KCl}$ solution was used for $3 \mathrm{~min}$. Finally, the cells were fixed, dripped, and stained by Giemsa (Solarbio). One thousand cells were randomly observed on each slide. Most of the micronucleus contained in the cells were round with smooth, neat edges. Their diameter was $1 / 16-1 / 3$ of the main nucleus, without refraction, not connected with the main nucleus, and consistent with chromophile, purplish or blue-purple. One or more micronucleus could appear in a cell. The number of cells with micronuclei is counted. Micronucleus cell rate $(\% o)$ $=$ total number of cells with micronucleus/total number of observed cells $\times 1000 \%$.

Quantitative real time polymerase chain reaction (qRT-PCR) assay. The expression of mRNA XPA, XPC, ERCC1, RPA1, and RPA2 were detected by qRT-PCR. Cells in the logarithmic growth phase were taken. Total RNA was extracted using TRIzol Reagent (Invitrogen, Carlsbad, CA, USA) and reverse transcribed to cDNA using the $\mathrm{RT}^{2}$ First Strand Kit according to the manufacturer's instructions (Qiagen, Duesseldorf, Germany). Gene expression level was detected according to the instructions of the $\mathrm{RT}^{2} \mathrm{SYBR}^{\circledR}$ Green qPCR Mastermix (Qiagen). qRT-PCR was performed in CFX96 ${ }^{\mathrm{TM}}$ Thermal Cycler (Bio-Rad). The formula $\Delta \mathrm{Ct}=\mathrm{Ct}$ average - average $\mathrm{Ct}$ of housekeeping genes, $\Delta \Delta \mathrm{Ct}=\Delta \mathrm{Ct}$ (experimental group) $-\Delta \mathrm{Ct}$ (control group), was used to calculate $\Delta \mathrm{Ct}$ and $\Delta \Delta \mathrm{Ct}$ value of the gene expression. 2- $\Delta \Delta \mathrm{Ct}$ was used to calculate the relative gene expression level of the experiment group. The primer details of XPA, XPC, ERCC1, RAP1, and RAP2 were shown in Table 1. 
Western blot analysis. Western blot detected the expression of XPA, XPC, ERCC1, RPA1, and RPA2 proteins. Cells in the logarithmic growth stage were taken and $200 \mu \mathrm{L}$ lysate solution (Biyuntian Biotechnology) was added. Cells were scraped with a cell scraper, collected, and centrifuged. Then the supernatant was collected and the loading buffer, at a ratio of 1:3, was added into supernatant before boiling it at $98^{\circ} \mathrm{C}$ and setting aside in the refrigerator at $-20^{\circ} \mathrm{C}$. The protein was separated by electrophoresis with $12 \%$ polyacrylamide gel. After membrane transfer with PVDF (Millipore Corporation, Burlington, MA, USA), the protein was sealed for $2 \mathrm{~h}$ by skimmed milk. The XPA, XPC, ERCC1, RAP1, and RAP2 antibody (1:1000, all from Ruiying Biological Co., Ltd.) was incubated at $4{ }^{\circ} \mathrm{C}$ overnight and the goat anti-rabbit antibody (1:4000, Ruiying Biological Co., Ltd.) was incubated at room temperature for $2 \mathrm{~h}$. The image was developed with ECL light agent (Cyagen Biosciences). The grayscale ratio of each target band and corresponding GAPDH was analyzed by Quantity One image analysis software (Bio-Rad) to represent the relative expression level of each protein.

Statistical analysis. Homogeneity test of variance and oneway ANOVA were used for comparison between groups. The statistical analysis of data obtained from each experiment used SPSS 26.0 for Windows software (Microsoft Corporation, Redmond, WA, USA). Values represented mean \pm standard deviation. The vakues *, ${ }^{*}$ [upper index) $\left.=\mathrm{zk}\right]$ and ${ }^{* *},{ }^{\# \#}$ denote $\mathrm{P}<0.05$ and $\mathrm{P}<0.01$, respectively which were considered to be statistically significant.

\section{Results}

\section{Protective effect of APS against cytotoxicity in BMSCs exposed to FA}

MTT assay was used to determine the cytotoxicity by calculating the proliferation rate of human BMSCs. MTT results (Fig. 1) showed that the cytotoxicity in FA-treated BMSCs increased significantly compared with control cells $(P<0.01)$ and cytotoxicity decreased significantly in cells incubated with FA plus APS at 40, 100 and $400 \mu \mathrm{g} / \mathrm{mL}$ compared with FA-treated BMSCs $(P<0.01)$. Among them, $100 \mu \mathrm{g} / \mathrm{mL}$ APS had the highest protective effect against cytotoxicity in BMSCs exposed to FA.

\section{Protective effect of APS against DNA breakage in BMSCs exposed to FA}

We used comet assay to identify DNA breakage in human BMSCs and DNA breakage was quantified as the OTM. The results (Fig. 2) showed that DNA breakage in BMSCs induced by FA was remarkably higher than that in control cells $(P<0.01)$. Compared with the FA-treated BMSCs, DNA breakage was significantly reduced in cells incubated with FA plus

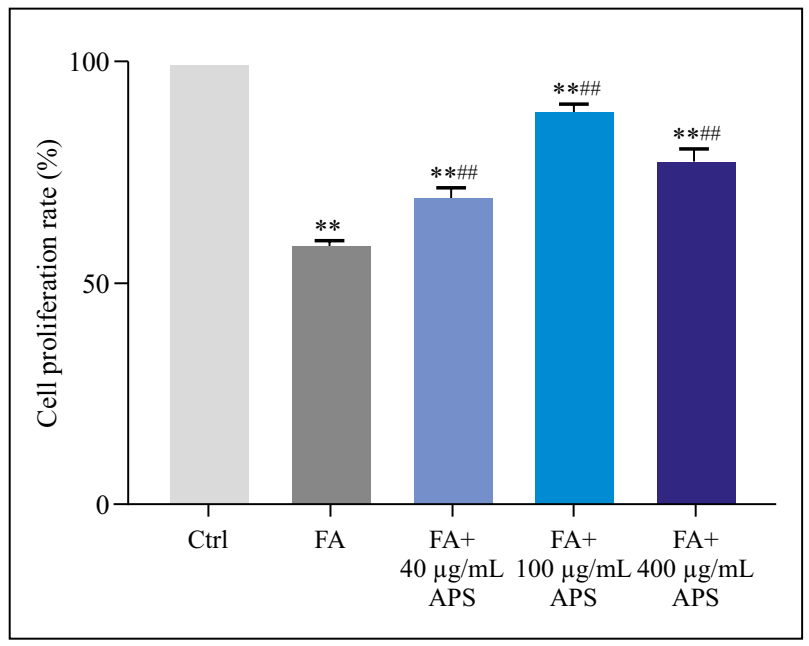

Figure 1. Astragalus polysaccharide (APS) reduced cytotoxicity in bone marrow mesenchymal stem cells (BMSCs) exposed to formaldehyde (FA). Human BMSCs were incubated in the D-MEM/F12 medium for $24 \mathrm{~h}$ in the presence of FA (120 $\mu \mathrm{mol} / \mathrm{L})$ and FA + APS at the concentrations of 40, 100 or $400 \mu \mathrm{g} / \mathrm{mL}$ as described in Methods. Cytotoxicity to BMSCs was determined by MTT test that assessed proliferation activity. Proliferation activity in human BMSCs exposed to FA decreased significantly compared with control (Ctrl) group. Cell proliferation activity increased significantly compared with that in FA + APS groups. ${ }^{*} P<0.05,{ }^{* *} P<0.01$ vs. Ctrl group. ${ }^{\#} P<0.05,{ }^{\# \#} P<0.01$ vs. FA group.

APS at 40,100 and $400 \mu \mathrm{g} / \mathrm{mL}(P<0.01)$. Among them, DNA breakage of cells treated with FA and $100 \mu \mathrm{g} / \mathrm{mL}$ was the least, and there was no significant difference compared with Ctrl group.

\section{Protective effect of APS against DPCs in BMSCs exposed to FA}

In order to determine DPCs formation in human BMSCs, KCl-SDS precipitation assay was used. The results (Fig. 3) showed that FA could significantly induce DPCs formation in BMSCs compared with Ctrl group $(P<0.01)$. Compared with the FA group, DPCs level was significantly reduced in cells incubated with FA plus APS at $40,100 \mu \mathrm{g} / \mathrm{mL}(P<0.01)$. However, when $400 \mu \mathrm{g} / \mathrm{mL}$ APS was used, the DPCs level increased but it was still significantly lower than that in the FA group $(P<0.01)$.

\section{Protective effect of APS against micronucleus in BMSCs exposed to FA}

The micronucleus assay results (Fig. 4) showed that the micronucleus frequency of FA-treated BMSCs was significantly increased compared with control cells $(P<0.01)$, and the micronucleus frequency was significantly decreased by the incubation of the cells with FA plus APS at the concentrations of 40,100, and 


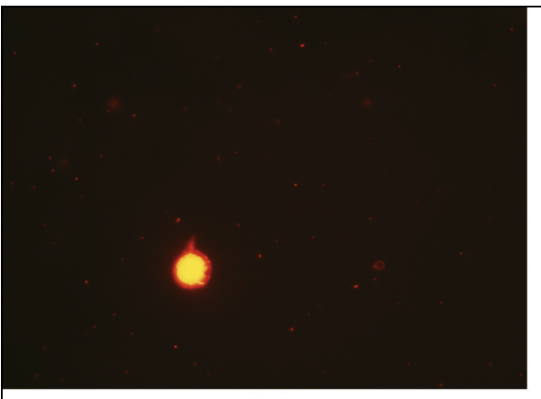

Ctrl

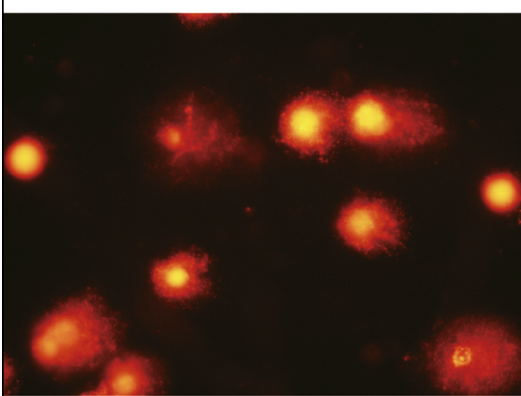

$\mathrm{FA}+100 \mu \mathrm{g} / \mathrm{mL}$ APS

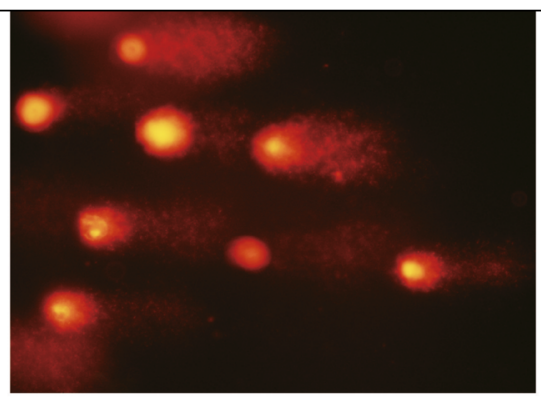

FA

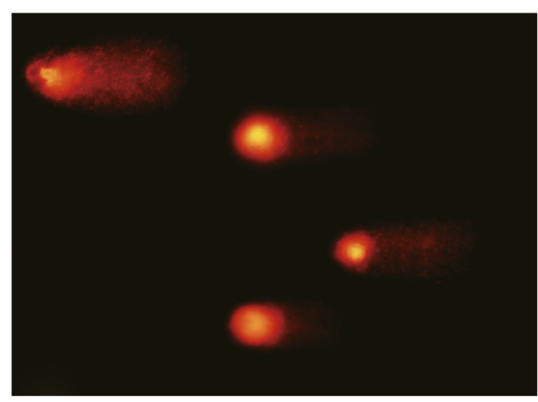

$\mathrm{FA}+400 \mu \mathrm{g} / \mathrm{mL}$ APS

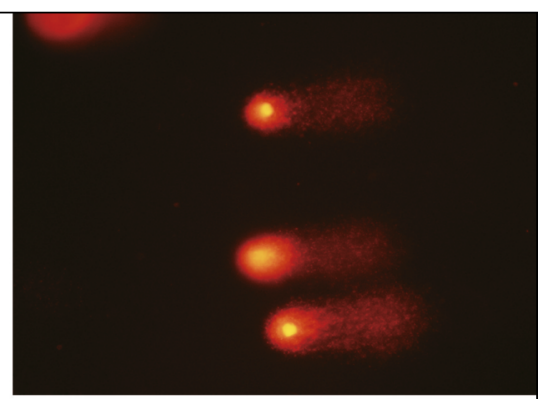

$\mathrm{FA}+40 \mu \mathrm{g} / \mathrm{mL}$ APS

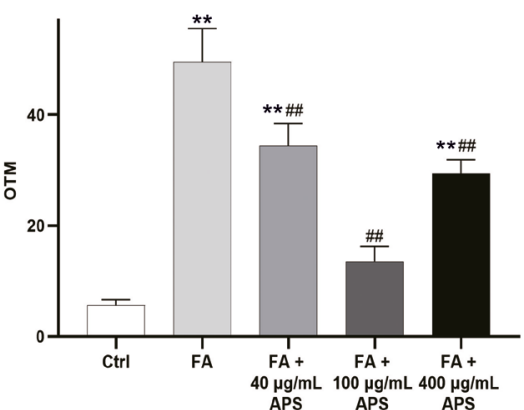

Figure 2. Astragalus polysaccharide (APS) reduced DNA breakage in BMSCs exposed to formaldehyde (FA). The comet assay was used to identify DNA breakage in human BMSCs. DNA breakage effect in human BMSCs exposed to FA was significantly higher than that in Ctrl group. Compared with FA group, DNA breakage in cells was significantly reduced in FA + APS groups. ${ }^{*} P<0.05,{ }^{*} P<0.01$ vs. control (Ctrl) group. ${ }^{\#} P<0.05,{ }^{\# \#} P<0.01$ vs. FA group. Magnification: $400 \times$.



Figure 3. Astragalus polysaccharide (APS) reduced DNA-protein crosslinks (DPCs) in BMSCs exposed to formaldehyde (FA). DPCs was measured by KCl-SDS precipitation assay as described in Methods. FA significantly increased the formation of DPCs in human BMSCs compared with that in control (Ctrl) group. Compared with FA group, DPCs in cells was significantly decreased in FA + APS groups. ${ }^{*} P<0.05$, ${ }^{* *} P<0.01$ vs. Ctrl group. ${ }^{\#} P<0.05,{ }^{\# \# P}<0.01$ vs. FA group.

$400 \mu \mathrm{g} / \mathrm{mL}(P<0.01)$. The micronucleus frequency of cells treated with FA and $100 \mu \mathrm{g} / \mathrm{mL}$ APS was the lowest among the FA plus APS groups at different concentrations.

\section{Effect of APS on the expression of XPA, XPC, ERCC1, RPA1 and RPA2 genes in NER pathway of BMSCs exposed to $F A$}

The results of qRT-PCR and Western blotting results (Fig. 5) showed that compared with the control cells, the expression of XPA protein, RPA1, RPA2 mRNA and protein were significantly down-regulated $(P<$ 0.01 ), and XPA mRNA, XPC, ERCC1 mRNA and protein were significantly up-regulated in FA-treated BMSCs $(P<0.01,0.05)$. Compared with the FA group, the mRNA and protein expression of XPA, XPC, ERCC1, RPA1, and RPA2 were all remarkably up-regulated in BMSCs incubated with FA plus each concentration of APS $(P<0.01,0.05)$. Of note, the gene expression reached a peak in BMSCs treated with FA plus $100 \mu \mathrm{g} / \mathrm{mL}$ APS.

\section{Discussion}

Our previous studies have confirmed that formaldehyde (FA) could inhibit the proliferative activity and enhance DNA-protein crosslinks (DPCs) formation in mice bone marrow mesenchymal stem cells (BMSCs) [7]. Therefore, the main purpose of this study was to investigate the protective effect of Astragalus polysaccharide (APS) against cytotoxicity and genotoxicity in human BMSCs exposed to FA and its potential mechanisms. In the present study, we found that the 


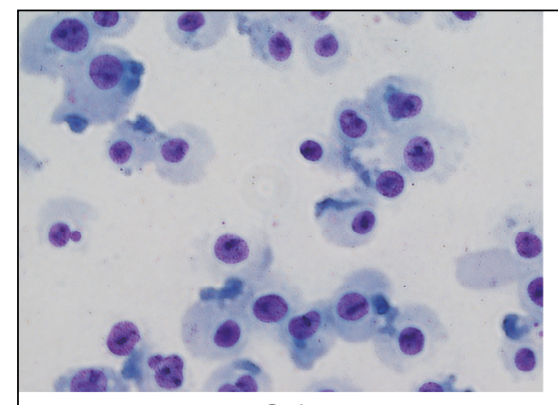

Ctrl

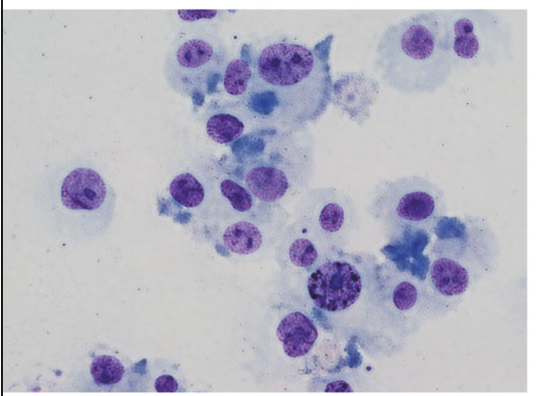

$\mathrm{FA}+100 \mu \mathrm{g} / \mathrm{mL}$ APS

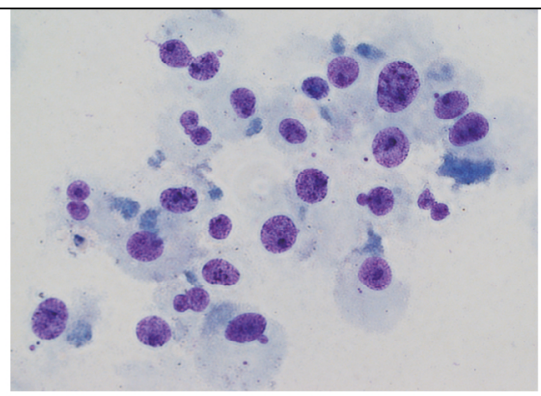

FA

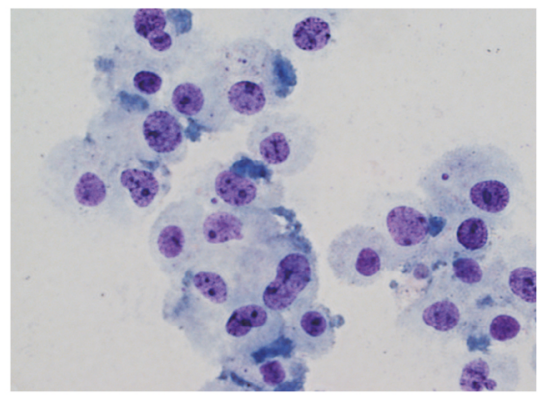

$\mathrm{FA}+400 \mu \mathrm{g} / \mathrm{mL}$ APS

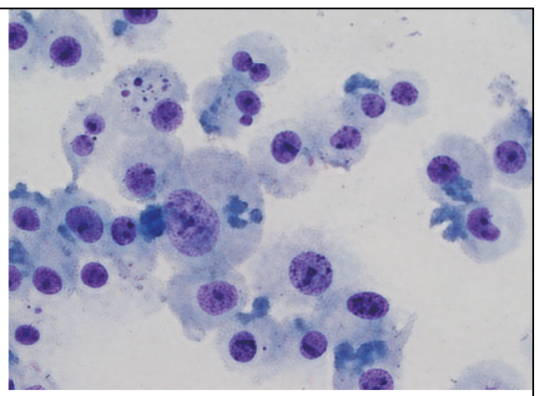

$\mathrm{FA}+40 \mu \mathrm{g} / \mathrm{mL}$ APS

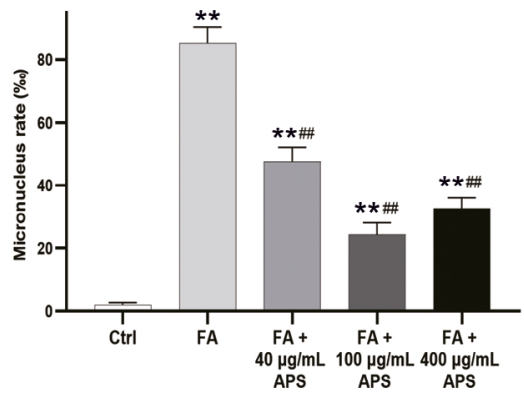

Figure 4. Astragalus polysaccharide (APS) decreased the micronucleus frequency in BMSCs exposed to formaldehyde (FA). The micronucleus frequency of human BMSCs was significantly increased in FA group compared with control (Ctrl) group. Compared with FA group, micronucleus frequency in cells was significantly decreased in FA + APS groups. ${ }^{*} P<0.05$, ${ }^{* *} P<0.01$ vs. Ctrl group. ${ }^{\#} P<0.05,{ }^{\#} P<0.01$ vs. FA group. Magnification: $400 \times$.

proliferation activity decreased in BMSCs exposed to FA, but the proliferation activity significantly increased after the cells were incubated with FA plus APS. These indicated that APS could reduce the cytotoxicity induced by FA in human BMSCs.

DNA breakage and DPCs formation are considered to be the main forms of DNA damage caused by FA [24]. It has even been reported that DPCs is a molecular marker of FA-related cancer risk [11, 25]. DPCs are necessary for DNA replication, transcription, and cell growth in normal cells; however, excessive DPCs produced by endogenous and exogenous agents block DNA replication resulting in genomic instability and tumorigenesis [26-28]. In this study, the degree of genotoxicity in BMSCs exposed to FA was studied by detecting the levels of DNA breakage, DPCs, and micronucleus formation. It was found that DNA breakage, DPCs and micronucleus formation in BMSCs exposed to FA were increased compared with control cells, however, after treatment with APS, they were decreased. This indicates that APS may protect against genotoxicity in BMSCs exposed to FA. This is consistent with study showing that APS can maintain genomic stability and reduce DNA damage in BMSCs incubated with the irradiated A549 cells [22, 29].

When external factors induce DNA damage, the cells can mobilize relevant repair mechanisms to reverse these damages in order to maintain genetic sta- bility. The nucleotide excision repair (NER) pathway, the major mechanism in the process of DNA repair, primarily eliminates bulky adducts arising from exposure to environmental agents [30-32]. Xeroderma pigmentosum group A (XPA) and xeroderma pigmentosum group C (XPC) are the initial recognizing proteins responsible for the recruitment of relevant repair apparatus components to the DNA damage site [33-35]. Excision repair cross-complementation group 1 (ERCC1) has a global function in cellular DNA damage repair [36]. ERCC1 binds to XPF to form the ERCC1-XPF complex, which is responsible for cutting the damage-containing oligonucleotide $[37,38]$. These core proteins involved in the NER reaction play a key role in the maintaining of genomic stability. Our study shows that the mRNA and protein expression levels of XPC and ERCC1 in FA-treated BMSCs were significantly higher than those in the control cells, indicating that XPC and ERCC1 may be involved in the repair of human BMSCs DNA damage caused by FA. This is in accordance with previous studies [7, 39]. The mRNA and protein expression levels of XPA, XPC, and ERCC1 in cells incubated with FA plus APS groups at different concentrations were significantly higher than those in the FA-treated cells. These findings demonstrate that APS promoted the repair of DNA damage by upregulating the mRNA and protein expressions of 


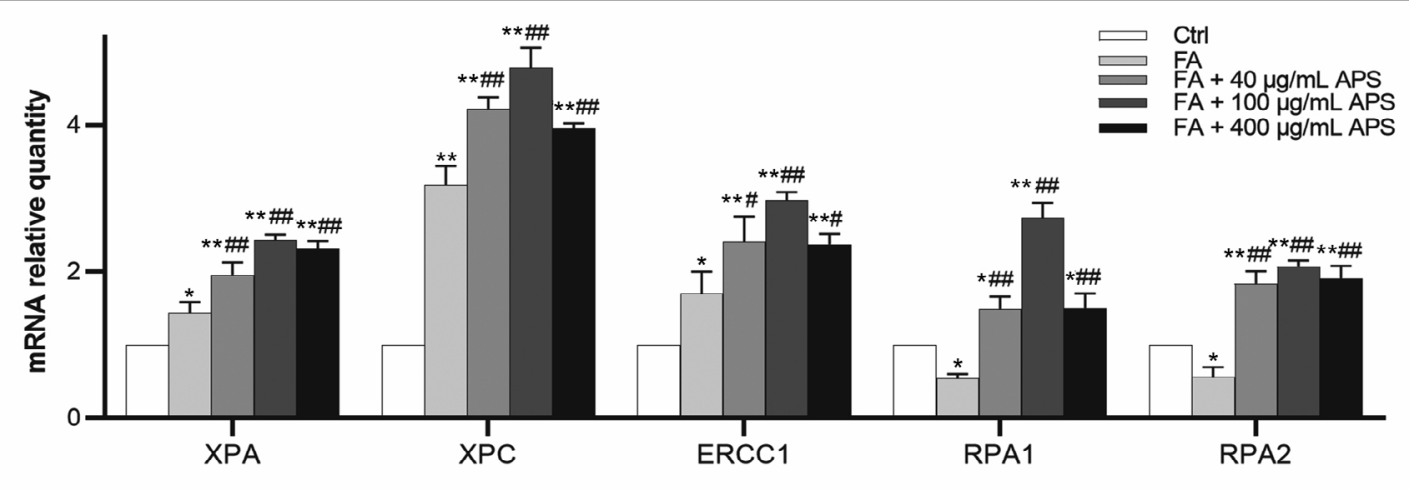

(A)


(B)

Figure 5. A. Astragalus polysaccharide (APS) up-regulated the mRNA expression of XPA, XPC, ERCC1, RPA1 and RPA2 in BMSCs exposed to formaldehyde. B. Astragalus polysaccharide (APS) up-regulated the protein expression of XPA, XPC, ERCC1, RPA1 and RPA2 in BMSCs exposed to formaldehyde. Relative levels of mRNA and protein content in the homogenates of BMSCs were measured by qRT-PCR and Western blotting as described in Methods. ${ }^{*} P<0.05,{ }^{* *} P<0.01$ vs. control (Ctrl) group. ${ }^{\#} P<0.05,{ }^{\# \#} P<0.01$ vs. FA group.

XPA, XPC, and ERCC1, which was consistent with the results that APS significantly reduced the DNA breakage, DPCs, and micronucleus formation in human BMSCs exposed to FA. A similar mechanism of was demonstrated in other reports [40, 41]. In addition, the study also found that the expression level of XPA mRNA in BMSCs treated by FA was higher than that in Ctrl group, while the expression level of XPA protein was decreased, which may be related to protein degradation, or may be affected by miRNA, progressive regulation from the translation level so that the protein was not expressed or XPA mRNA was directly degraded.

Replication protein A (RPA), a eukaryotic single-stranded DNA binding protein, is composed of three related subunits: RPA1 (RPA70), RPA2 (RPA32), and RPA3 (RPA14). Much progress has been made to elucidate the critical roles for RPA in DNA metabolic pathways that help promote genomic stability [42]. RPA is not only involved in the initiation, extension of DNA replication, and the organization of Okazaki fragments but is also involved in NER repair. RPA can protect single-stranded DNA from nuclear degradation and hairpin formation after DNA damage [43]. At the same time, RPA1 and RPA2 can bind to XPA to form the RPA-XPA complex, which is involved in the recognition of DNA damage [44]. In this study, we found that the mRNA and protein expression of RPA1, RPA2 decreased in FA-treated cells compared with control cells, indicating that RPA1, RPA2 did not participate in the repair of DNA damage caused by FA. On the other hand, DNA damage caused by FA blocks the cell cycle and DNA 
replication, so the mRNA and protein expression of replication-related genes RPA1 and RPA2 were decreased in FA-treated cells. Compared with the FA group, the mRNA and protein expressions of RPA1, RPA2 in BMSCs incubated with FA plus each concentration of APS were significantly increased, suggesting that APS may promote the recognition of RPA1, RPA2, and DNA damage, and help in the formation of RPA-XPA complex, thus ensuring the smooth progression of NER. A similar mechanism of was demonstrated to be functional in study showing that XPA combined with RPA might be involved in damage-recognition in NER [40].

This study also found that the protective effect of APS on BMSCs treated by FA reached the peak when concentration of APS was $100 \mu \mathrm{g} / \mathrm{mL}$. However, when APS mass concentration is greater than $100 \mu \mathrm{g} / \mathrm{mL}$, APS may have toxic effects on BMSCs and aggravate DNA damage. These findings suggested that although APS may promote DNA repair, there is still a certain safe range of the mass concentration when it is used. However, the in vitro experiments, have a limited relevance to the whole body system. Drugs in the body have to go through absorption, distribution, and first-pass effects, and their functions are also affected by complex factors such as neuroendocrine and immune systems. Therefore, experiments in vivo are needed to further determine the effective concentration of APS or to link the concentration that produces toxicity in vitro with the corresponding dose in vivo.

In conclusion, APS has a significant protective effect against FA-induced cytotoxicity and genotoxicity of BMSCs, especially at the concentration of $100 \mu \mathrm{g} / \mathrm{mL}$, which may be related to the up-regulation of gene expression of XPA, XPC, ERCC1, RPA1, and RPA2 in the NER pathway and the promotion of DNA damage repair. However, its specific safe dose range in vivo remains to be further studied and defined.

\section{Acknowledgment}

This study was supported by the National Natural Science Foundation of China (grant number 81560667), the National Natural Science Foundation of Gansu Province, China (grant number 1506RJZA045), the Provincial-Level Key Laboratory of Molecular Medicine of Major Diseases and Study on Prevention and Treatment of Traditional Chinese Medicine, Gansu University of Chinese Medicine, China (grant number FZYX17-18-7) and Longyuan Youth Innovation and Entrepreneurship Talent Project, Gansu University of Chinese Medicine, China (grant number LYQN2021-2).

\section{Conflict of interest}

The authors hereby declare that they do not have any conflicting interest.

\section{References}

1. Moore KA, Lemischka IR. Stem cells and their niches. Science. 2006; 311(5769): 1880-1885, doi: 10.1126/science.1110542, indexed in Pubmed: 16574858.

2. Méndez-Ferrer S, Michurina TV, Ferraro F, et al. Mesenchymal and haematopoietic stem cells form a unique bone marrow niche. Nature. 2010; 466(7308): 829-834, doi: 10.1038/ nature09262, indexed in Pubmed: 20703299.

3. Zhang L, Freeman LE, Nakamura J, et al. Formaldehyde and leukemia: epidemiology, potential mechanisms, and implications for risk assessment. Environ Mol Mutagen. 2010; 51(3): 181-191, doi: 10.1002/em.20534, indexed in Pubmed: 19790261.

4. Chemical agents and related occupations. IARC Monogr Eval Carcinog Risks Hum. 2012; 100: 9-562, indexed in Pubmed: 23189753.

5. Zhang L, Tang X, Rothman N, et al. Occupational exposure to formaldehyde, hematotoxicity, and leukemia-specific chromosome changes in cultured myeloid progenitor cells. Cancer Epidemiol Biomarkers Prev. 2010; 19(1): 80-88, doi: 10.1158/1055-9965.EPI-09-0762, indexed in Pubmed: 20056626.

6. Liang X, Zhang J, Song W, et al. Formaldehyde exposure in indoor air from public places and its associated health risks in Kunshan City, China. Asia Pac J Public Health. 2018; 30(6): 551-560, doi: 10.1177/1010539518800348, indexed in Pubmed: 30221985.

7. She Y, Li Yi, Liu Y, et al. Formaldehyde induces toxic effects and regulates the expression of damage response genes in BM-MSCs. Acta Biochim Biophys Sin (Shanghai). 2013; 45(12): 1011-1020, doi: 10.1093/abbs/gmt105, indexed in Pubmed: 24077345.

8. Ortega-Atienza S, Wong VC, DeLoughery Z, et al. ATM and KAT5 safeguard replicating chromatin against formaldehyde damage. Nucleic Acids Res. 2016; 44(1): 198-209, doi: 10.1093/nar/gkv957, indexed in Pubmed: 26420831.

9. Zhang S, Chen H, Zhang J, et al. The multiplex interactions and molecular mechanism on genotoxicity induced by formaldehyde and acrolein mixtures on human bronchial epithelial BEAS-2B cells. Environ Int. 2020; 143: 105943, doi: 10.1016/j. envint.2020.105943, indexed in Pubmed: 32659531.

10. Liang FQ, Godley B. Oxidative stress-induced mitochondrial DNA damage in human retinal pigment epithelial cells: a possible mechanism for RPE aging and age-related macular degeneration. Exp Eye Res. 2003; 76(4): 397-403, doi: 10.1016/s0014-4835(03)00023-x.

11. Hubal EA, Schlosser PM, Conolly RB, et al. Comparison of inhaled formaldehyde dosimetry predictions with DNA-protein cross-link measurements in the rat nasal passages. Toxicol Appl Pharmacol. 1997; 143(1): 47-55, doi: 10.1006/ taap.1996.8076, indexed in Pubmed: 9073591.

12. Latimer JJ, Johnson JM, Kelly CM, et al. Nucleotide excision repair deficiency is intrinsic in sporadic stage I breast cancer. Proc Natl Acad Sci U S A. 2010; 107(50): 21725-21730, doi: 10.1073/pnas.0914772107, indexed in Pubmed: 21118987.

13. Vrouwe MG, Pines A, Overmeer RM, et al. UV-induced photolesions elicit ATR-kinase-dependent signaling in non-cycling cells through nucleotide excision repair-dependent and 
-independent pathways. J Cell Sci. 2011; 124(Pt 3): 435-446, doi: 10.1242/jcs.075325, indexed in Pubmed: 21224401.

14. Salem AMH, Nakano T, Takuwa M, et al. Genetic analysis of repair and damage tolerance mechanisms for DNA-protein cross-links in Escherichia coli. J Bacteriol. 2009; 191(18): 5657-5668, doi: 10.1128/JB.00417-09, indexed in Pubmed: 19617358

15. Yeung K, Gubili J, Cassileth B. An evidence-based review of Astragalus membranaceus (Astragalus) for cancer patients. Evidence-based Anticancer Materia Medica. 2011: 65-84, doi: 10.1007/978-94-007-0526-5_3.

16. Jung Y, Jerng U, Lee S. A systematic review of anticancer effects of radix astragali. Chin J Integr Med. 2016; 22(3): 225-236, doi: 10.1007/s11655-015-2324-x, indexed in $\mathrm{Pu}-$ bmed: 26643507.

17. $\mathrm{Wu} \mathrm{J}, \mathrm{Yu} \mathrm{J}$, Wang J, et al. Astragalus polysaccharide enhanced antitumor effects of Apatinib in gastric cancer AGS cells by inhibiting AKT signalling pathway. Biomed Pharmacother. 2018; 100: 176-183, doi: 10.1016/j.biopha.2018.01.140, indexed in Pubmed: 29428665.

18. Liu T, Zhang M, Niu H, et al. Astragalus polysaccharide from Astragalus Melittin ameliorates inflammation via suppressing the activation of TLR-4/NF- $\kappa \mathrm{B}$ p 65 signal pathway and protects mice from CVB3-induced virus myocarditis. Int J Biol Macromol. 2019; 126: 179-186, doi: 10.1016/j.ijbiomac.2018.12.207, indexed in Pubmed: 30586589.

19. Zheng Y, Ren W, Zhang L, et al. A review of the pharmacological action of Astragalus polysaccharide. Front Pharmacol. 2020; 11: 349, doi: 10.3389/fphar.2020.00349, indexed in Pubmed: 32265719.

20. Chen M, May BH, Zhou IW, et al. Oxaliplatin-based chemotherapy combined with traditional medicines for neutropenia in colorectal cancer: A meta-analysis of the contributions of specific plants. Crit Rev Oncol Hematol. 2016; 105: 18-34, doi: 10.1016/j.critrevonc.2016.07.002, indexed in Pubmed: 27497028.

21. Zhang PP, Meng ZT, Wang LC, et al. Astragalus polysaccharide promotes the release of mature granulocytes through the L-selectin signaling pathway. Chin Med. 2015; 10: 17, doi: 10.1186/s13020-015-0043-z, indexed in Pubmed: 26161135.

22. Zhang LY, Yong WX, Wang L, et al. Astragalus polysaccharide eases G1 phase-correlative bystander effects through mediation of TGF- R/MAPK/ROS signal pathway after carbon ion irradiation in BMSCs. Am J Chin Med. 2019; 47(3): 595-612, doi: 10.1142/S0192415X19500319, indexed in $\mathrm{Pu}-$ bmed: 31122040.

23. Yang F, Yan G, Li Y, et al. Astragalus polysaccharide attenuated iron overload-induced dysfunction of mesenchymal stem cells via suppressing mitochondrial ROS. Cell Physiol Biochem. 2016; 39(4): 1369-1379, doi: 10.1159/000447841, indexed in Pubmed: 27607448.

24. Liu Y, Li CM, Lu Z, et al. Studies on formation and repair of formaldehyde-damaged DNA by detection of DNA-protein crosslinks and DNA breaks. Front Biosci. 2006; 11: 991-997, doi: 10.2741/1856, indexed in Pubmed: 16146790.

25. Formaldehyde, 2-butoxyethanol and 1-tert-butoxypropan-2-ol. IARC Monogr Eval Carcinog Risks Hum. 2006; 88: 1-478, indexed in Pubmed: 17366697.

26. Ji S, Thomforde J, Rogers C, et al. Transcriptional Bypass of DNA-Protein and DNA-Peptide Conjugates by T7 RNA Polymerase. ACS Chem Biol. 2019; 14(12): 2564-2575, doi: 10.1021/acschembio.9b00365, indexed in Pubmed: 31573793.

27. Ji S, Fu I, Naldiga S, et al. 5-Formylcytosine mediated DNA-protein cross-links block DNA replication and induce mutations in human cells. Nucleic Acids Res. 2018; 46(13): 6455-6469, doi: 10.1093/nar/gky444, indexed in Pubmed: 29905846.

28. Permana PA, Snapka RM. Aldehyde-induced protein-DNA crosslinks disrupt specific stages of SV40 DNA replication. Carcinogenesis. 1994; 15(5): 1031-1036, doi: 10.1093/carcin/15.5.1031, indexed in Pubmed: 8200064.

29. Zhang L, Luo Y, Lu Z, et al. Astragalus polysaccharide inhibits ionizing radiation-induced bystander effects by regulating MAPK/NF-kB signaling pathway in bone mesenchymal stem cells (BMSCs). Med Sci Monit. 2018; 24: 4649-4658, doi: 10.12659/MSM.909153, indexed in Pubmed: 29976920.

30. Zhu J, Fu W, Jia W, et al. Association between NER pathway gene polymorphisms and wilms tumor risk. Mol Ther Nucleic Acids. 2018; 12: 854-860, doi: 10.1016/j.omtn.2018.08.002, indexed in Pubmed: 30161024.

31. Kojima Y, Machida YJ. DNA-protein crosslinks from environmental exposure: Mechanisms of formation and repair. Environ Mol Mutagen. 2020; 61(7): 716-729, doi: 10.1002/ em.22381, indexed in Pubmed: 32329115.

32. Baker DJ, Wuenschell G, Xia L, et al. Nucleotide excision repair eliminates unique DNA-protein cross-links from mammalian cells. J Biol Chem. 2007; 282(31): 22592-22604, doi: 10.1074/jbc.M702856200, indexed in Pubmed: 17507378.

33. Buschta-Hedayat N, Buterin T, Hess MT, et al. Recognition of nonhybridizing base pairs during nucleotide excision repair of DNA. Proc Natl Acad Sci U S A. 1999; 96(11): 6090-6095, doi: 10.1073/pnas.96.11.6090, indexed in Pubmed: 10339546.

34. Wood R. DNA damage recognition during nucleotide excision repair in mammalian cells. Biochimie. 1999; 81(1-2): 39-44, doi: 10.1016/s0300-9084(99)80036-4, indexed in Pubmed: 10214908

35. Yasuda G, Nishi R, Watanabe E, et al. In vivo destabilization and functional defects of the xeroderma pigmentosum $\mathrm{C}$ protein caused by a pathogenic missense mutation. Mol Cell Biol. 2007; 27(19): 6606-6614, doi: 10.1128/MCB.02166-06, indexed in Pubmed: 17682058.

36. Servant G, Streva VA, Derbes RS, et al. The nucleotide excision repair pathway limits L1 retrotransposition. Genetics. 2017; 205(1): 139-153, doi: 10.1534/genetics.116.188680, indexed in Pubmed: 28049704.

37. Sijbers A, Laat Wde, Ariza R, et al. Xeroderma pigmentosum group $\mathrm{F}$ caused by a defect in a structure-specific DNA repair endonuclease. Cell. 1996; 86(5): 811-822, doi: 10.1016/s00928674(00)80155-5, indexed in Pubmed: 8797827.

38. O’Donovan A, Davies AA, Moggs JG, et al. XPG endonuclease makes the 3' incision in human DNA nucleotide excision repair. Nature. 1994; 371(6496): 432-435, doi: 10.1038/371432a0, indexed in Pubmed: 8090225.

39. Cassee FR, de Burbure CY, Rambali B, et al. Subchronic inhalation of mixtures of cigarette smoke constituents in Xpa/-p53+/- knock-out mice: a comparison of intermittent with semi-continuous exposure to acetaldehyde, formaldehyde, and acrolein. Food Chem Toxicol. 2008; 46(2): 527-536, doi: 10.1016/j.fct.2007.08.043, indexed in Pubmed: 17936466.

40. Saijo M, Kuraoka I, Masutani C, et al. Sequential binding of DNA repair proteins RPA and ERCC1 to XPA in vitro. Nucleic Acids Res. 1996; 24(23): 4719-4724, doi: 10.1093/ nar/24.23.4719, indexed in Pubmed: 8972858.

41. Lindsey-Boltz LA, Kemp MG, Reardon JT, et al. Coupling of human DNA excision repair and the DNA damage checkpoint in a defined in vitro system. J Biol Chem. 2014; 289(8): 5074-5082, doi: 10.1074/jbc.M113.542787, indexed in Pubmed: 24403078 . 
42. Byrne BM, Oakley GG. Replication protein A, the laxative that keeps DNA regular: The importance of RPA phosphorylation in maintaining genome stability. Semin Cell Dev Biol. 2019; 86: 112-120, doi: 10.1016/j.semcdb.2018.04.005, indexed in Pubmed: 29665433.

43. Krasikova YS, Rechkunova NI, Maltseva EA, et al. Localization of xeroderma pigmentosum group A protein and replication protein A on damaged DNA in nucle- otide excision repair. Nucleic Acids Res. 2010; 38(22): 8083-8094, doi: 10.1093/nar/gkq649, indexed in Pubmed: 20693538 .

44. Krasikova YS, Rechkunova NI, Maltseva EA, et al. RPA and XPA interaction with DNA structures mimicking intermediates of the late stages in nucleotide excision repair. PLoS One. 2018; 13(1): e0190782, doi: 10.1371/journal.pone.0190782, indexed in Pubmed: 29320546.

Submitted: 26 January, 2021 Accepted after reviews: 10 May, 2021 Available as AoP: 19 May, 2021 